\title{
Characterization of Thermo-Physical Properties of Cement-Based Blocks of Varied Sand Types Using Cost-Effective Enhancement Approach
}

\author{
Eunice Akyereko Adjei1 ${ }^{*}$, Samuel Amos-Abanyie², Siddig Omer ${ }^{3}$ \\ ${ }^{1}$ Department of Mech. Eng., Kwame Nkrumah University of Science and Technology, Kumasi, Ghana \\ ${ }^{2}$ Department of Architecture, Kwame Nkrumah University of Science and Technology, Kumasi, Ghana \\ ${ }^{3}$ Department of Architecture and Built Environment, University of Nottingham, Nottingham, UK \\ Email: *s.a.abanyie@gmail.com
}

How to cite this paper: Adjei, E.A., Amos-Abanyie, S. and Omer, S. (2020) Characterization of Thermo-Physical Properties of Cement-Based Blocks of Varied Sand Types Using Cost-Effective Enhancement Approach. Open Journal of Energy Efficiency, 9, 14-30.

https://doi.org/10.4236/ojee.2020.91002

Received: December 13, 2019

Accepted: March 9, 2020

Published: March 12, 2020

Copyright $\odot 2020$ by author(s) and Scientific Research Publishing Inc. This work is licensed under the Creative Commons Attribution International License (CC BY 4.0).

http://creativecommons.org/licenses/by/4.0/

\begin{abstract}
The dominant property of building envelope fabric which contributes significantly to minimize electricity utilization in building is the thermo-physical properties. There is inadequate literature on representative practical data of thermo-physical properties of the dominant building envelope components in Ghana. This study aims to use cost-effective approach to characterize the thermo-physical properties of only cement-based mortar and concrete blocks used in Ghana for building components specifically wall design. Mixed methods research design was employed to achieving the aim. A questionnaire survey was used among sampled building fabric components manufacturers to pick representative data on thermos-physical properties of their mortar and concrete blocks. Also, an experimental procedure employing a transient technique with a TCi Thermal Analyser was used to determine the thermo-physical properties of selected mortar and concrete blocks from Ghana in addition to designed parametric mortar and concrete blocks with varied ratios obtained from the survey were undertaken at University of Nottingham. From the study, a trend of decreasing thermal conductivity and thermal effusivity with corresponding decreasing sand content was observed with all the different sand types. The thermal conductivities of both mortar and concrete parametric blocks meet the range of expected standard values outlined in Chattered Institute of Building Services Engineers (CIBSE) Guide A. The major limitation of the work is the dimension of the sample size; which is not inconsistent with standard block size due to the experimental setup used. It is expected that, the characterization of the predominant cement-based building fabrics components will contribute to improved building performance analysis with significant savings in electricity utilization for space cooling.
\end{abstract}




\section{Keywords}

Building Envelop, Thermal Conductivity, Thermal Effusivity, TCi Thermal

Analyser, Cement-Based Fabric, Cost-Effective Enhancement Approach, Ghana

\section{Introduction}

In recent years, attention has been paid to reducing energy consumption in buildings towards achieving a Net Zero Energy Building (NZEB). The building sector has been the second largest energy consuming sector after transportation with $28 \%$ of final global energy consumption [1] [2] [3] [4] thus presenting a significant potential for energy savings and greenhouse gas emissions reduction. Adoption of high-performing building envelope is regarded as a prerequisite to reduce energy consumption of buildings because it is the main barrier of protection from heat transfer [5]. Studies by [6] [7] established that a building's cooling load, and by extension the energy consumption, correlates with heat transfer through the building envelope [6]. Therefore, minimizing heat transfer through building envelope is crucial for reducing cooling load. The selection of building fabrics should be carefully considered to enhance their potential in minimizing heat and moisture transfer through building components for improved performance, and consequently, the energy and indoor environmental quality [8]-[13].

There are other measures that enhance building performance such as controlling solar gain through window, thermostat set point, building control systems, programmable thermostat, and architectural design parameters such as building form, window properties, thermal insulation level. Techniques such as application of passive cooling techniques, high-reflectivity coating on building walls, air tightness, phase change materials, reduction of u-values, daylighting harvesting all contributed to efficient energy use and improved indoor environmental quality in buildings [14]-[20].

In spite of the above techniques, [21] asserts that, Ghana experiences high cooling load in air-conditioned buildings and thermal discomfort in naturally ventilated buildings as a result of low levels of integration of high-performance technologies in buildings, and this has been attributed largely to their high cost.

There are a number of indigenous building envelope fabric available in the developing world, including sand, clay, laterite, wood, bamboo, stones, and cement-based fabric [22]. Among the indigenous fabric, a number of studies have been carried out on clay, the most abundant material, to valorise its use for thermal insulation applications [23]. The physio-chemical properties of soils can be altered or modified by adding stabilizers (admixtures) such as cement and lime, a process termed as soil-stabilization. However, cement-based materials such as mortar and concrete blocks have remained the most predominant material for use as building envelope materials in Ghana [21] [22]. The Cabinet of Ghana passed a bill in 2010 that at least $60 \%$ of the content used in construction of public buildings to be made up of indigenous raw materials. 
A gap exists in literature on practical data of thermo-physical properties of materials used as envelope in buildings in the Sub-Saharan countries [10]. Several factors such as surface area, thickness, thermal transmittance, among others influences heat transfer into building envelope. The unavailability of thermo-physical properties of the most commonly used building envelope fabric leads to either an overestimation or underestimation of cooling load in the sizing of HVAC system for buildings. In instances of overestimation, there is wastage in the energy consumption for space conditioning. On the other hand, the underestimation of cooling load leads to indoor environmental conditions being compromised. Previous studies on building performance in Ghana, have been based on thermo-physical properties provided in building analysis software packages developed, predominantly for the temperate world. Such instances necessitated much demanding calibration procedures to validate confounding factors associated with variations in thermo-physical properties [10] [13] [24] [25].

Thermo-physical properties of permeable materials are affected by several factors, for example thermal contacting agent, porosity, compactness among others [8] [18]. Blocks with relatively lower cement content turn to have larger size pores and blocks with higher cement content turn to have large number of smaller pores. [26] study shows the variation of total pore volume under different bulk densities of the same standard brick materials and was found that, denser materials were found to have lower total pore volume, thereby resulting in high conductive heat transfer.

In the context of the above, the aim of this study was to characterize the thermo-physical properties of mortar and concrete blocks made from the available types of sand in Ghana using cost-effective enhancement approach. The study sought to: 1) explore the thermo-physical properties of mortar and concrete blocks using a questionnaire survey among selected building fabric manufacturers in Ghana; 2) To compare the thermo-physical properties of mortar and concrete blocks selected from building fabric manufacturers with representative values from the CIBSE Guide values; and 3) to determine the thermo-physical properties of the parametric mortar and concrete blocks made from various sand types based on the dominant mixing ratio identified from the survey to determine the best sand type and mixing ratio for lower thermo-physical properties.

It is expected that, the characterization of the mortar and concrete blocks, being the predominant building envelope fabrics, will contribute to improve building thermal performance analysis, with significant savings in energy consumption for space cooling.

\section{Thermo-Physical Test Method}

Several thermos-physical test methods exist in both scientific and technical journals research, among them are steady [27] [28] and transient state techniques [29]. Steady state technique offer simple measurements methods without any complex means of analysis, conversely, it has relatively long time in reaching 
stationary conditions for fabrics with great thermal inertia with no change in temperature with time, examples are Sears bar method and Lees disc method. Whiles, transient technique incorporates one or more heat flux meters in the stack of plates calibrated against standard samples whose conductivity was previously measured using the absolute approach. It offers relatively detailed measurements and fast readings, on the other hand, it requires a complex data processing as well as high expertise in the heat source. Examples of transient test method include, modified transient plane source, hot wire method, hot plate method, heat flow meter, laser flash analysis method. The accuracy of the test method is crucial to determining the thermal conductivity and effusivity of the material. In simple terms, thermal conductivity and effusivity are both properties of the material which measures with the ability to conduct heat and the behaviour of the heat storing or dissipating capability respectively.

\section{Methodology}

The procedures involved in the questionnaire survey among a sampled building fabric manufacturer and the experimental setup to determine the thermo-physical properties are explained in this section.

\subsection{Questionnaire Survey}

The questionnaire was of mixed open and close format. Due to the dispersed nature of building fabric manufacturers in Ghana, snowball sampling technique was used to identify six (6) leading large scale building manufacturers in Ghana. This survey was necessary to determine the implementation of thermal building regulation of manufactured fabrics in Ghana. The survey was carried out via Bristol Online Survey Tool for sorting and processing of data for analysis. Data accuracy was paramount; hence login details were integrated into the questionnaire link restricting access to participants outside the cluster studied. The survey data were analysed using descriptive analysis. Some selected questions include the following:

1) Do you implement the thermal building regulations in the cement-based manufactured products from your company?

Yes/No.

2) Select the typical thermal conductivity $(\mathrm{W} / \mathrm{mK})$ of your concrete products?
a) $0.03-0.3$
b) $0.3-0.7$
c) $0.7-1.0$
d) $1.0-1.6$
e) $1.6-2.2$
f) I do not know
g) Other (please specify)
3) Select the representative thermal conductivity $(\mathrm{W} / \mathrm{mK})$ of your mortar blocks?
a) $0.03-0.5$
b) $0.5-0.75$
c) $0.75-0.95$
d) $0.95-1.2$
e.1.2 - 1.6
f) I do not know
g) Other (please specify)

\subsection{Experimental Set-Up for TCi Thermal Conductivity Analyzer}

A TCi Thermal Conductivity Analyzer which is based on modified transient plane source was used to determine the thermo-physical properties in the Nottingham 
University, UK. There were two sets of samples: 1) randomly selected building fabrics from the stock of the manufacturing companies in Ghana; and 2) developed parametric mortar and concrete blocks. The TCi Thermal Conductivity Analyzer comprises of a TCi Sensor, C-Therm Unit, Data Acquisition System (laptop), and power control device as represented in Figure 1 and Figure 2. The functioning of the TCi Conductivity Analyzer, procedures and steps for, and number of test measurement readings of the C-Therm software parameters for the surfaces of the specimen are explained in [30]. The thermal conductivity values were evaluated in comparison to the Chattered Institute of Building Services Engineers (CIBSE) Guide A.

Preliminary test was carried out to establish the validity and reliability of the experimental setup. The results of Pyrex glass using polymer test method with TCi Thermal Conductivity Analyzer compared with manufacturer's expected values for both thermal conductivity and thermal effusivity showed percentage

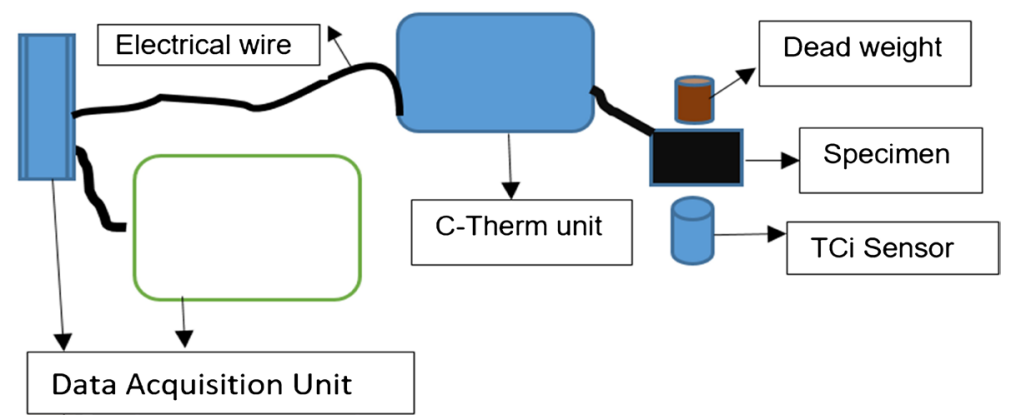

Figure 1. Experimental setup of TCi thermal conductivity analyzer.

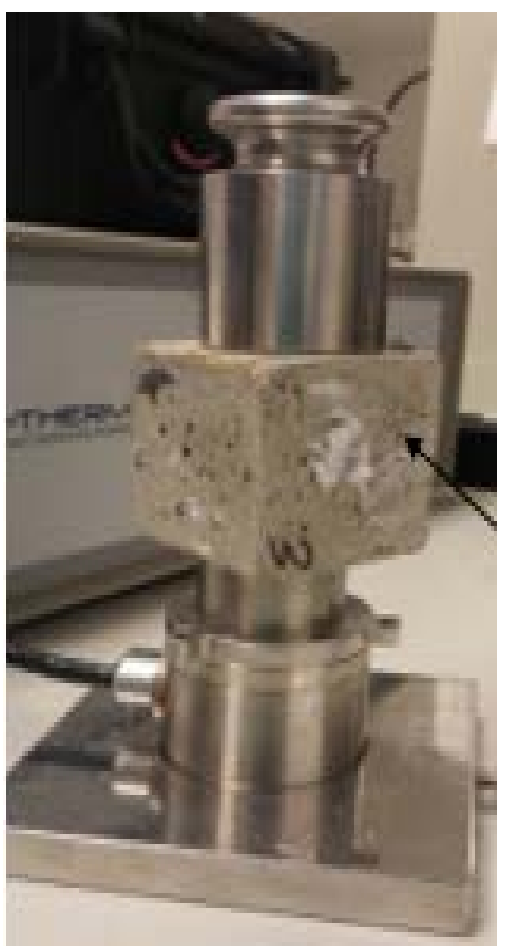

Figure 2. CTi Sensor with specimen and dead weight. 
deviation of $7.1 \%$ and $0.7 \%$ respectively. This implied that, the error arising from the measurement of the set-up is minor and hence negligible. The procedures employed in the preparation of manufacturers samples and parametric mortar and concrete blocks for testing are explained in the following sections.

\subsubsection{Preparation of Selected Mortar and Concrete Blocks for Testing}

Due to the significant $80 \%$ of building manufacturers response in agreement of implementing thermal building regulations, randomly selected building fabrics were sent for experimental investigations to ascertain typical properties indicated in the survey. A series of tasks involving four stages were carried out prior to the main thermo-physical test measurement: 1) measurement of weight and dimensions of samples; 2) division of each samples into at least 6 parts, labelled with anonymous names and for a radioactive test by Ghana Atomic Energy for customs clearance for shipping to the UK as shown in Figure 3(v); 3) moisture control of the specimen in UK were carried out as a result of moisture transfer and temperature variation between Ghana and UK. The experiments blocks were at ambient temperature of $25^{\circ} \mathrm{C}$ with a moisture content of $10 \%$; and 4) reduction of sizes and surface finishing of specimen as represented in Figure 3.

\subsubsection{Preparation of Parametric Mortar and Concrete Blocks for Testing} The following series of tasks were employed to develop parametric mortar and concrete blocks: 1) Specification of parametric mortar and concrete blocks; and 2) Design and Casting of samples.

\section{1) Specification of parametric mortar and concrete blocks}

A set of 15 each of parametric mortar blocks and concrete blocks of five dominant representative ratios of Portland cement, mixed size gavels (10 - 20 $\mathrm{mm}$ ), and sand types used in Ghana from the survey were designed and developed at the University of Nottingham for the experiment.
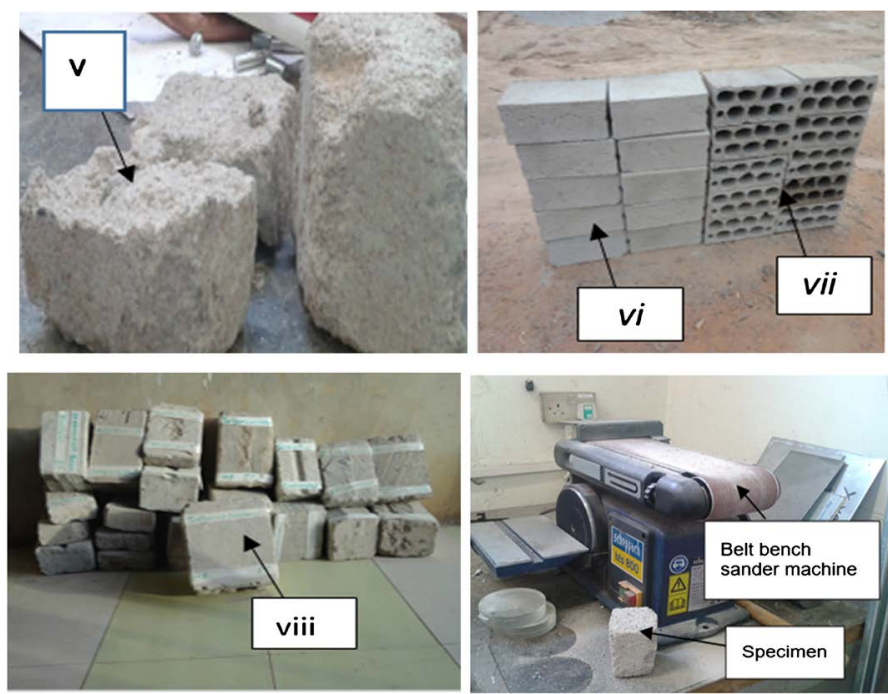

$V=$ Moisture controlled sample size; $v i=$ Selected solid cement-based block amples; $v i i=$ Selected hollow cement-based block samples; viii = Prepared cement-based samples for shipping.

Figure 3. Activities of representative buiding fabric samples preparation. 
Representative ratios of mortar blocks and concrete blocks are presented below:

Ratios (Cement: Sand type) for mortar blocks:

$\mathrm{T}_{1}=1: 5 ; \mathrm{T}_{2}=1: 6 ; \mathrm{T}_{3}=1: 3 ; \mathrm{T}_{4}=1: 2 ;$ and $\mathrm{T}_{5}=1: 4$.

Ratios (Cement: Gravels: Sand type) for concrete blocks:

$\mathrm{T}_{11}=1: 3: 1 ; \mathrm{T}_{22}=1: 4: 1 ; \mathrm{T}_{33}=1: 5: 1 ; \mathrm{T}_{44}=1: 1: 3 ;$ and $\mathrm{T}_{55}=1: 1: 4$.

The sand types were i) washed sand; ii) builders' sand; and iii) mixed washed and builders' sand, thus resulting in five ratios for each types of sand, making a total of 15 parametric blocks for each of mortar and concrete. The builder's sand was selected in accordance with [31] standards whiles the washed sand was selected in accordance with [32] standards.

Ratios of parametric mortar blocks and concrete blocks are presented below:

Various (5) ratios of mortar with washed sand type are defined as:

MwsT1, MwsT2, MwsT 3 , MwsT4 and MwsT5.

Various (5) ratios of mortar with builder's sand type are defined as:

MbsT1, MbsT2, MbsT 3 , MbsT4 and MbsT5.

Various (5) ratios of mortar with mixed washed and builders sand types are defined as:

MbwsT1, MbwsT2, MbwsT 3 , MbwsT4 and MbwsT5.

Various (5) ratios of concrete with washed sand type are defined as:

Cws $_{11} ; \mathrm{CwsT}_{22} ; \mathrm{CwsT}_{33} ; \mathrm{CwsT}_{44} ;$ and $\mathrm{CwsT}_{55}$.

Various (5) ratios of concrete with builder's sand type are defined as:

$\mathrm{CbsT}_{11} ; \mathrm{Cbs}_{22} ; \mathrm{CbsT}_{33} ; \mathrm{CbsT}_{44} ;$ and $\mathrm{CbsT}_{55}$

Various (5) ratios of concrete with mixed washed and builders sand types are defined as:

$\mathrm{CbwsT}_{11}, \mathrm{CbwsT}_{22}, \mathrm{CbwsT}_{33}, \mathrm{CbwsT}_{44}$ and $\mathrm{CbwsT}_{55}$.

\section{2) Design and Casting of samples}

The preparation of specimen moulds, casting of the concrete samples and compaction were guided by [33] [34]. Wooden boxes of unit size of $50 \mathrm{~mm} \times 50 \mathrm{~mm}$ $\times 50 \mathrm{~mm}$ was used for casting the parametric mortar blocks and the concrete blocks (Figure 4(a)). Mortar and concrete blocks are dry after 28 days of ambient
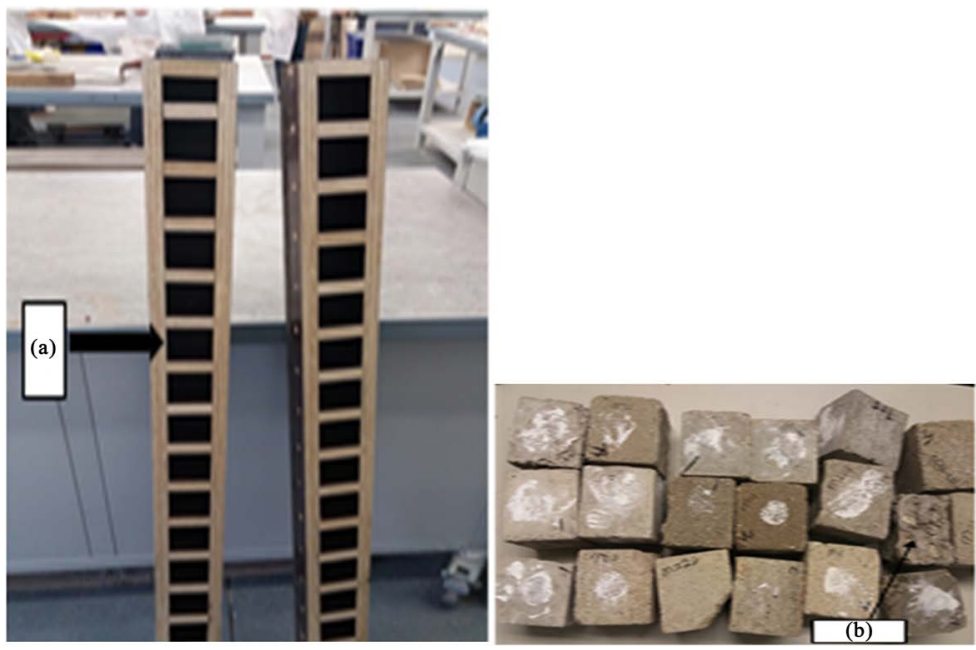

Figure 4. (a) Parametric casting boxes; (b) Some tested sample blocks. 
drying period per specifications of [35] and was further tested using simple moisture experiment, that is, three days continuous weighing of samples to ascertain there were no more variation in weight. Figure 4(b) presents samples of the tested parametric blocks.

\section{Results and Discussions}

The discussion of the results has been categorized into three areas: Representative Thermo-physical properties from survey; Thermo-physical properties of selected existing building fabrics in Ghana; and Thermo-physical properties of parametric mortar and concrete blocks using varying mixing design ratios from survey and varying sand types.

\subsection{Representative Thermo-Physical Properties from Survey}

The representative thermal conductivity of the selected mortar block and concrete block samples are presented in Figure 5 and Figure 6 . The Figures show that, respondents specified varied ranges of thermal conductivities for the samples.

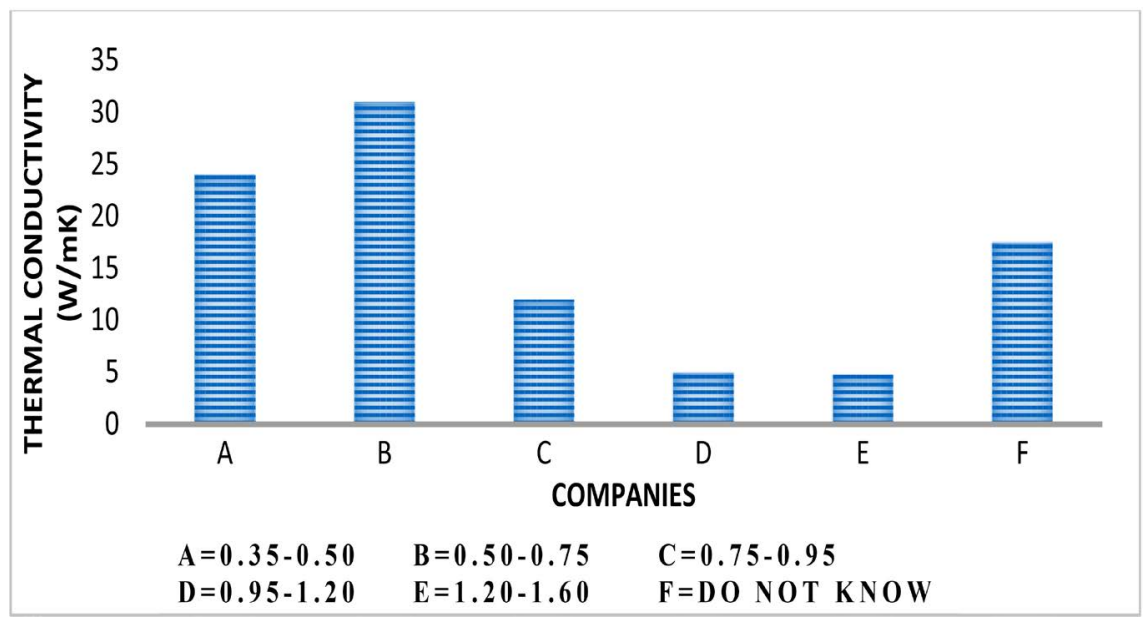

Figure 5. Manufacturer's specified thermal conductivity of mortar block.

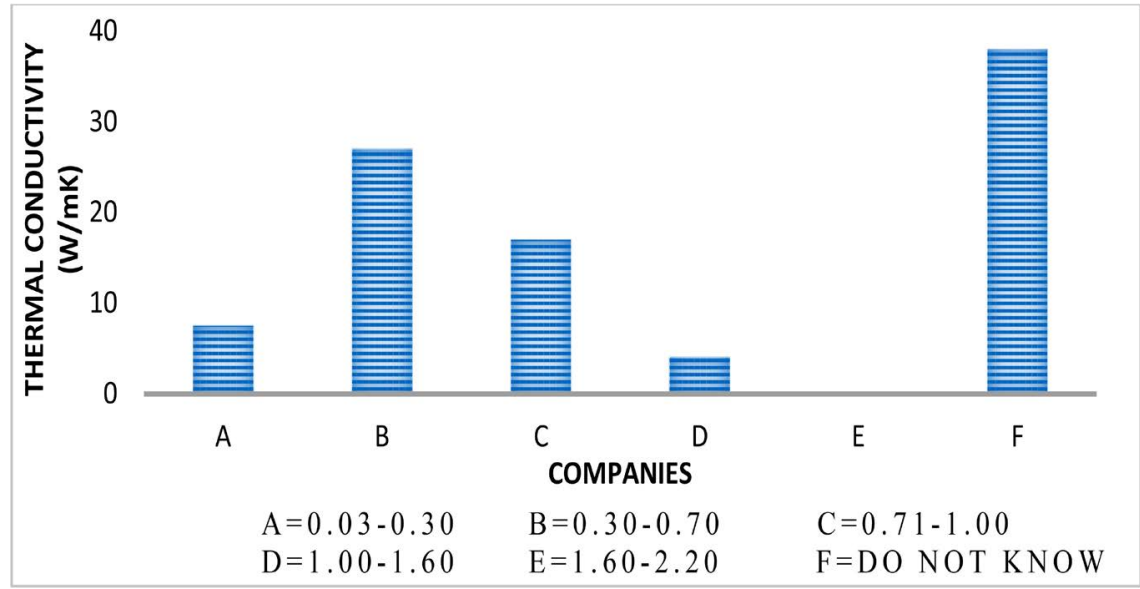

Figure 6. Manufacturer's specified thermal conductivity of concrete block. 
As seen in Figure 5, 30\% participants indicated thermal conductivity of mortar block in the range of $0.5-0.75 \mathrm{~W} / \mathrm{mK}$, and $19 \%$ indicated that they do not know the thermal conductivity. With respect to the concrete block samples, respondents indicated varied thermal conductivites from $0.03-1.6 \mathrm{~W} / \mathrm{mK}$ in Figure 6. $33 \%$ of respondents indicated that they do not know the thermal conductivity for concrete blocks.

\subsection{Thermo-Physical Properties of Selected Existing Building Fabrics in Ghana}

It was assumed that, for the same sand, mixing design ratios, as well as the use of these standards [33] [34] [35] irrespective of the dimension of the block's dimension, the experimental thermal conductivity remains the same.

The thermal conductivity of mortar block and concrete block from the selected building fabric manufacturers in Ghana are compared with the CIBSE Guide A range of values in Figure 7 and Figure 8. Companies $A, B$ and $C$, the thermal conductivity of mortar blocks was $0.36 \mathrm{~W} / \mathrm{mK}, 0.35 \mathrm{~W} / \mathrm{mK}$ and $0.19 \mathrm{~W} / \mathrm{mK}$ respectively. With respect to concrete blocks, companies $\mathrm{A}, \mathrm{B}$ and $\mathrm{C}$ have thermal conductivity values of $0.47 \mathrm{~W} / \mathrm{mK}, 0.69 \mathrm{~W} / \mathrm{mK}$ and $0.62 \mathrm{~W} / \mathrm{mK}$ respectively. In CIBSE Guide A, thermal conductivity values for mortar block and concrete block are $0.70 \mathrm{~W} / \mathrm{mK}$ and $0.76 \mathrm{~W} / \mathrm{mK}$ respectively. The thermal conductivity of the sample blocks from the companies have lower values compared to CIBSE Guide A.

With respect to the survey data in Figure 5, the thermal conductivity of the mortar blocks produced are in the range of 0.5 to $0.7 \mathrm{~W} / \mathrm{mK}$. However, the experimental results show that the majority of the mortar blocks have thermal conductivity within the range of $0.21-0.36 \mathrm{~W} / \mathrm{mK}$. Likewise, the survey results in Figure 6 shows that the indicated thermal conductivity for concrete blocks fabric is in the same range as that of the experimental results from sample concrete blocks from Ghana in Figure 8, that is, $0.3-0.76 \mathrm{~W} / \mathrm{mK}$.

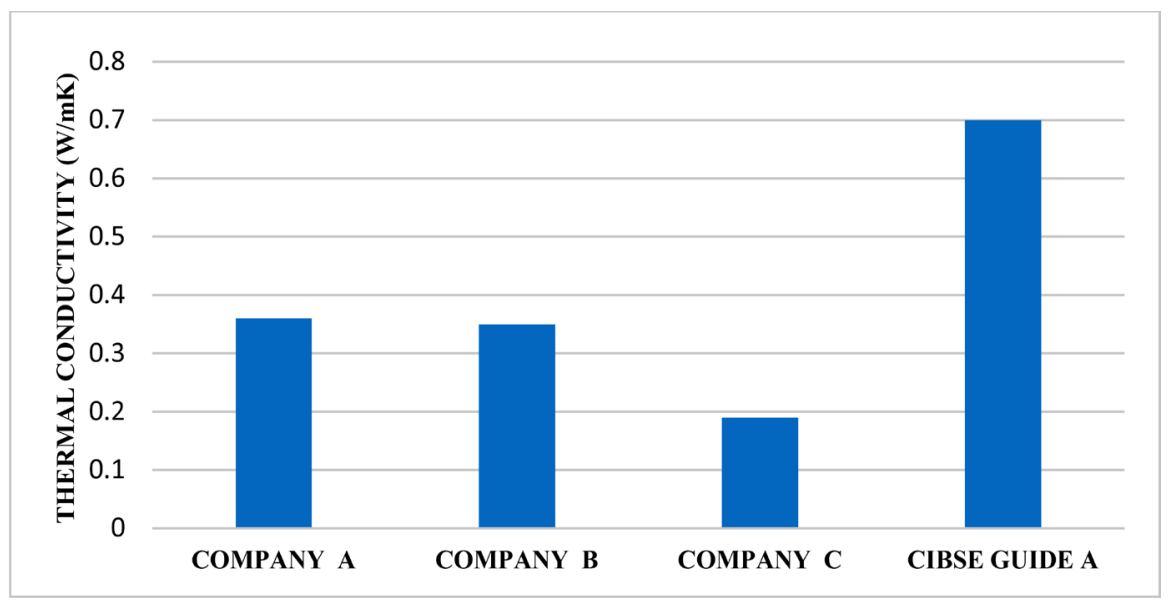

Figure 7. Thermal conductivity of polymer test method for selected mortar block companies in comparison with CIBSE Guide A. 
The thermal effusivity of mortar block and concrete block samples are presented in Figure 9 and Figure 10. Thermal effusivity values varied from 615 $\mathrm{Ws} s^{1 / 2} / \mathrm{m}^{2} \mathrm{~K}$ to $1060 \mathrm{Ws}^{1 / 2} / \mathrm{m}^{2} \mathrm{~K}$ for the specimens collected from the companies. A trend of decreasing thermal effusivity with decreasing thermal conductivity was observed. This implies that thermal contacting agent used in Polymer test method for thermal conductivity measurements has no effect on thermo-physical properties.

\subsection{Thermo-Physical Properties of Parametric Mortar and Concrete Blocks}

The thermal conductivity and thermal effusivity of the parametric mortar and concrete blocks determined by TCi Thermal Conductivity Analyzer based on modified transient plane source are presented in this section.

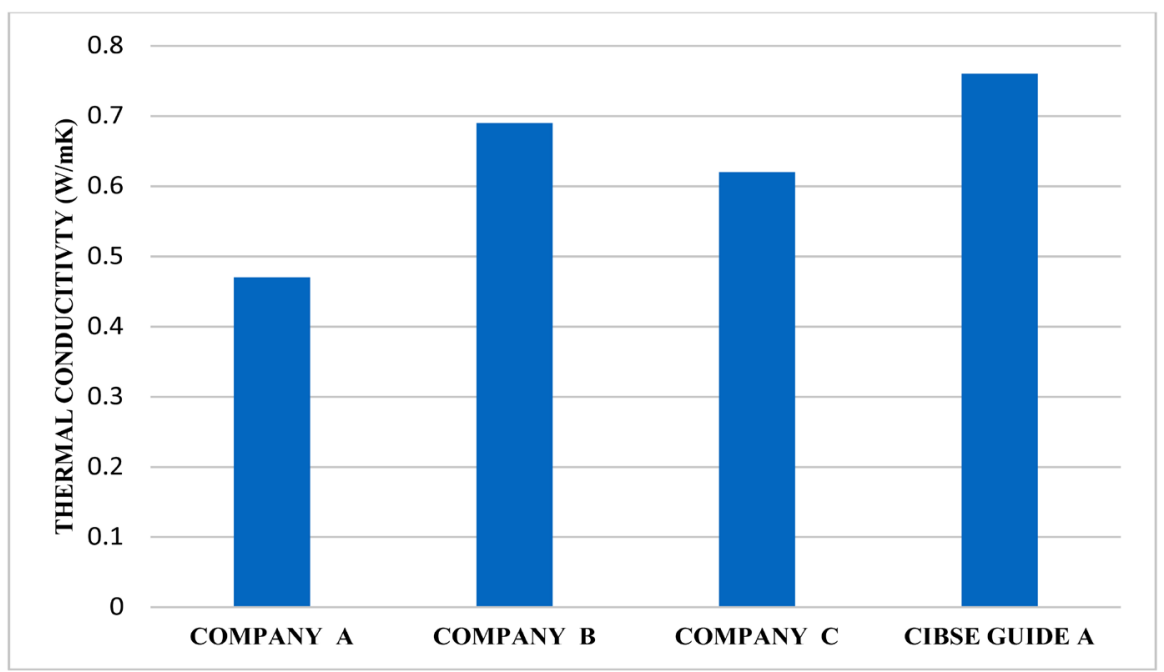

Figure 8. Thermal conductivity of polymer test method for selected concrete blocks companies in comparison with CIBSE Guide A.

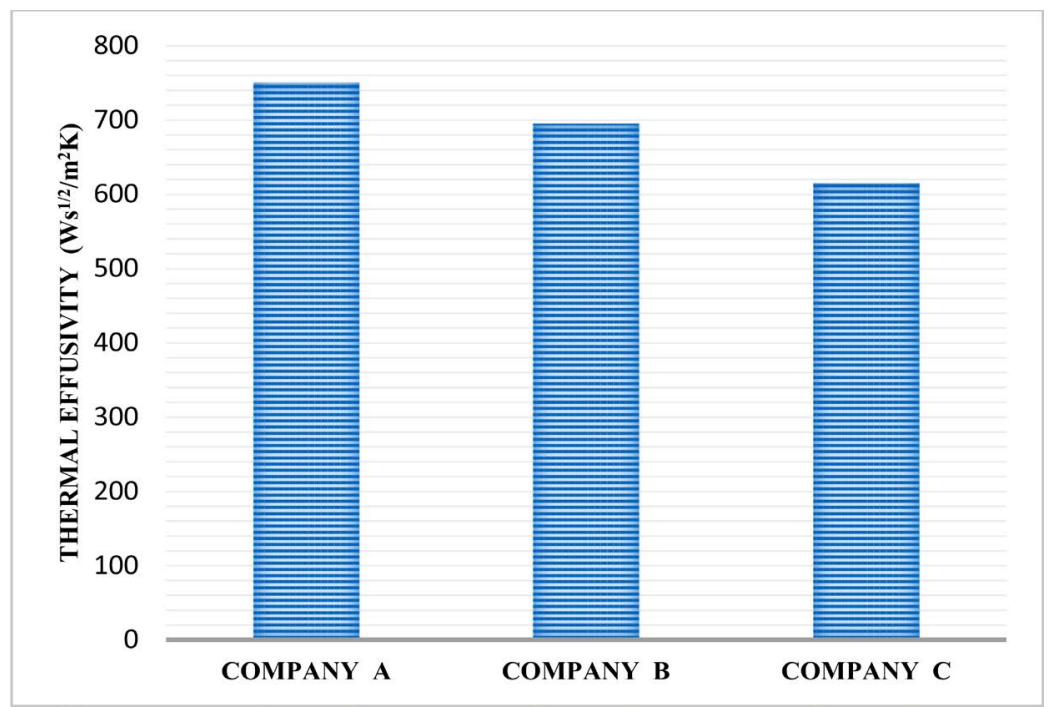

Figure 9. Average thermal effusivity of polymer test method for selected mortar block companies in Ghana. 


\subsubsection{Thermal Conductivity}

The effect of the various ratios of the parametric mortar and concrete blocks on thermal conductivity is presented in Figure 11 and Figure 12. All the parametric mortar blocks have thermal conductivity in the range of the polymer test method as specified in the CIBSE Guide A. The thermal conductivity of parametric mortar blocks lies in the range of $0.200 \mathrm{~W} /(\mathrm{mK})$ to $0.610 \mathrm{~W} /(\mathrm{mK})$ for the different mixing ratios for washed, builder's and mixed washed and builder's sand types. With the decrease in the sand content, there is a general decrease of between

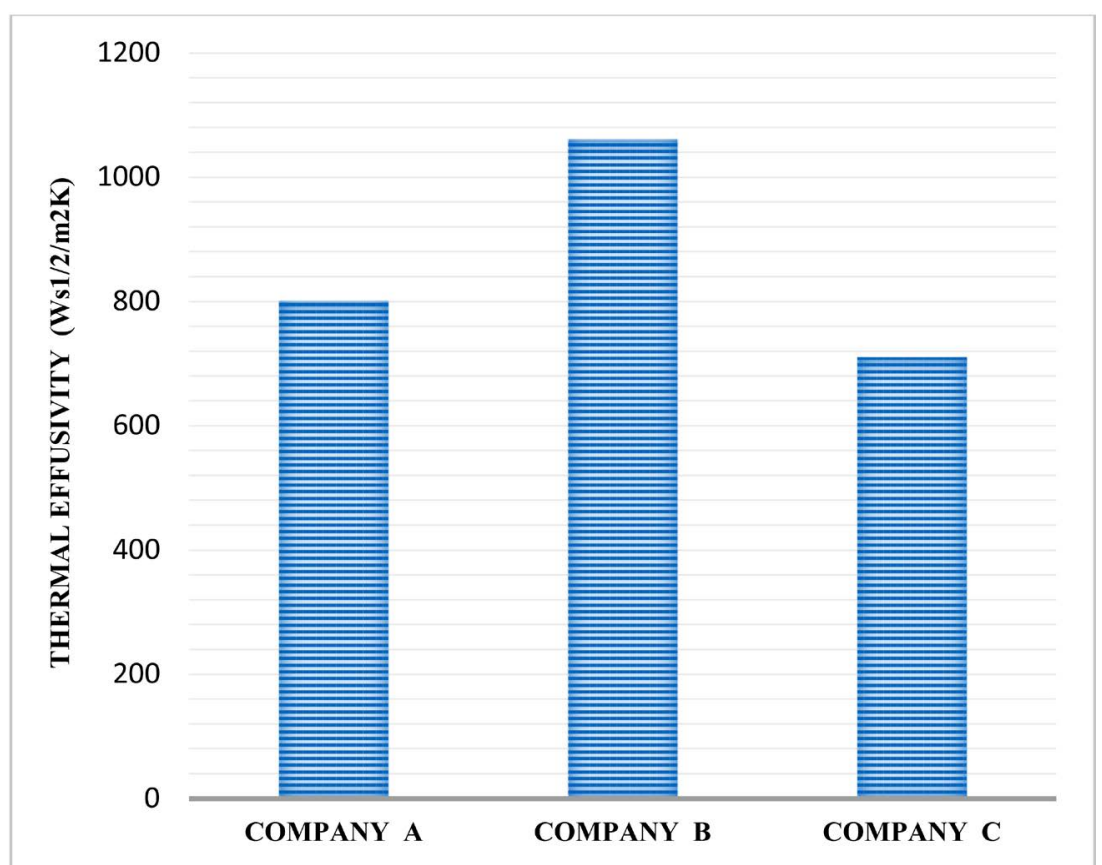

Figure 10. Average thermal effusivity of polymer test method for selected concrete block companies in Ghana

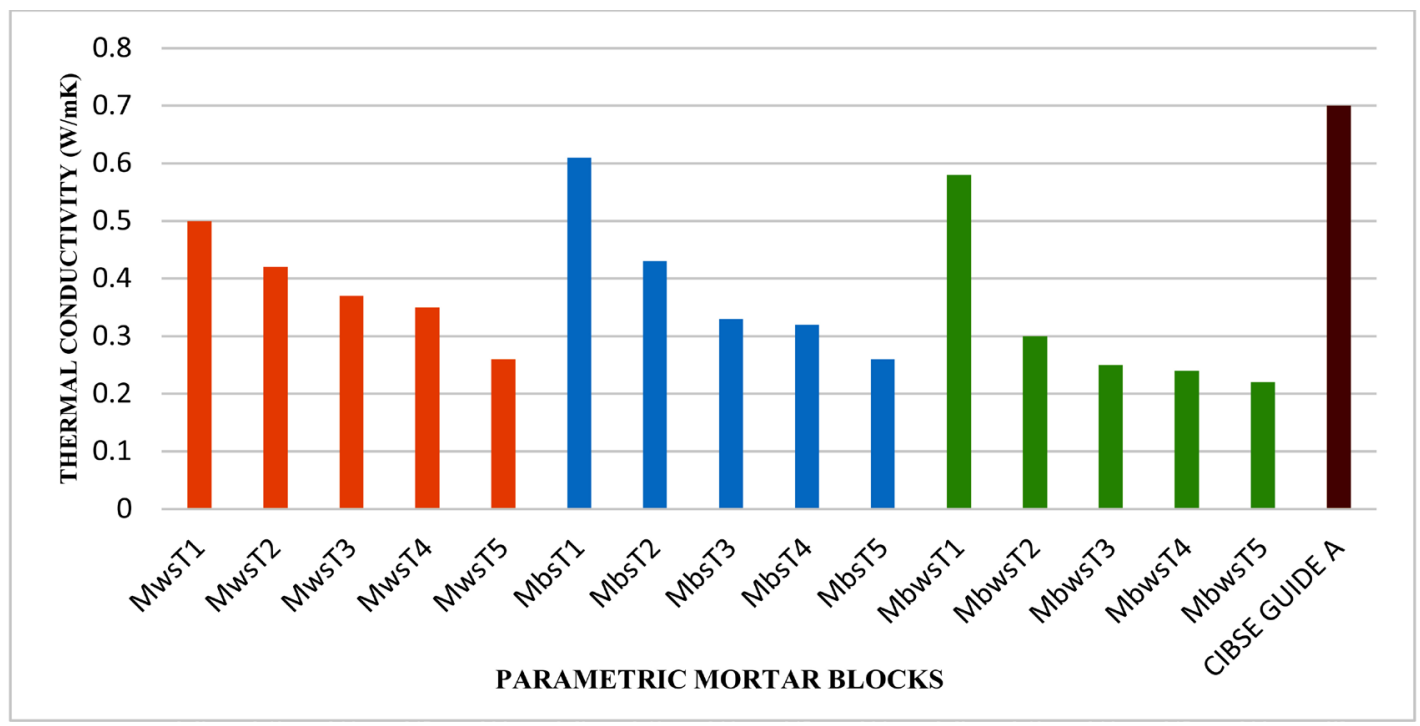

Figure 11. Comparison of average thermal conductivity of polymer test method for parametric mortar blocks with CIBSE Guide A. 
$20 \%$ and $45 \%$ of the thermal conductivity for all the different sand types and combinations. For example, $\mathrm{MbsT}_{1}$ (with 1 part of cement to 6 parts of sand) had thermal conductivity of $0.51 \mathrm{~W} / \mathrm{mK}$ and $\mathrm{MbsT}_{5}$ ( 1 part of cement to 2 parts of sand) had thermal conductivity of $0.28 \mathrm{~W} / \mathrm{mK}$. This implies that, assuming all the conditions which can affect the experimental results (mixture uniformity, compactness of blocks, minimal porosity, right contacting agent, standard level of dryness of sample, among others) are equal, decreasing sand content of the block lead to decreased thermal conductivity. However, uses of the various types of sand for the various ratios do not have substantial impact on the thermal conductivity. No substantial deviation in thermal conductivity was observed among the sand types. The mixed sand type had lowest thermal properties among the sand types albeit a small margin.

As the cement content of the block increases, as associated with $\mathrm{MwsT}_{1}, \mathrm{MbsT}_{1}$ and $\mathrm{MbwsT}_{1}$, the total pore volume is reduced and tends to increase heat flow through the block by increasing thermal conductivity [36] [37]. The reduced pore volume could be attributed to the hydration products in the pores of the blocks [36] [38].

A rather narrow range of $0.250 \mathrm{~W} /(\mathrm{mK})$ to $0.390 \mathrm{~W} /(\mathrm{mK})$ was achieved for the thermal conductivity of parametric concrete blocks for the different mixing ratios of cement, gravels and sand as presented in Figure 12. With the decrease in the sand content, there is a general decrease of between $20 \%$ and $45 \%$ of the thermal conductivity for all the different sand types and combination. For example, Cbs $_{11}$ (with 1 part of cement to 3 parts of gravels and 1 part of sand) had thermal conductivity of $0.39 \mathrm{~W} / \mathrm{mK}$ for all the sand types and $\mathrm{Cbs}_{55}$ (with 1 part of cement to 1 part of gravels and 4 parts of sand) had thermal conductivity of $0.25 \mathrm{~W} / \mathrm{mK}$ for all the sand types. Among the ratios for combined builder's

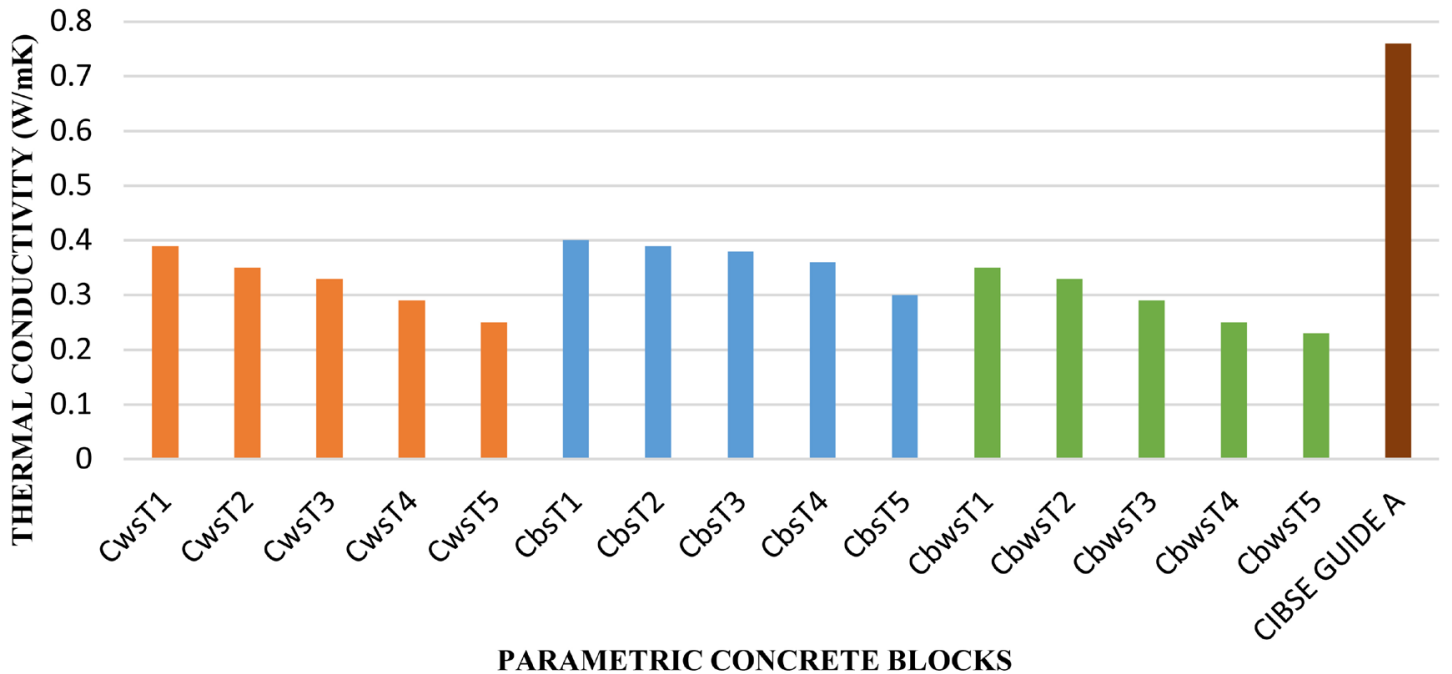

Figure 12. Comparison of average thermal conductivity of polymer test method for parametric concrete blocks with CIBSE Guide A. 
and washed sand concrete blocks, Cbws $\mathrm{T}_{11}$ (with 1 part of cement to 3 parts of gravels and 1 part of sand) had thermal conductivity of $0.37 \mathrm{~W} / \mathrm{mK}$ and Cbws $_{55}$ (with 1 part of cement to 1 part of gravels and 4 part of sand) had thermal conductivity of $0.24 \mathrm{~W} / \mathrm{mK}$. There is no appreciable variation in thermal conductivity among the mixes for the various sand types. This implies that the differences in thermal conductivity results mainly from the varied ratios of cement, gravels and sand and for a given sand type.

From the assumption above, and using a typical standard block dimension with the obtained cost-effective thermal conductivity, the thermal transmittance of a single leaf wall use in Ghana can be estimated using Equation (1) and Equation (2) as follows:

Typical thickness of mortar block $=5 "(0.127)$;

Typical thickness for lightweight internal plaster $=0.5 "(0.013 \mathrm{~m})$;

Typical thickness for lightweight external plaster $=0.5$ " $(0.013 \mathrm{~m})$;

Typical thermal conductivity for lightweight internal plaster $=0.18 \mathrm{~W} / \mathrm{mK}$;

Typical thermal conductivity for lightweight external plaster $=0.18 \mathrm{~W} / \mathrm{mK}$;

Average thermal conductivity for cost effective parametric mortar $=0.405 \mathrm{~W} / \mathrm{mK}$.

For a solid material: Thermal resistance $R=d / \lambda$

where $d=$ thickness (depth) of material layer, $\lambda=$ thermal conductivity of the material

$$
\text { Thermal Transmittance } U=1 / R t
$$

where $R t$ is the total thermal resistance.

The summarized $U$-value of a typical wall at Ghana is shown in Table 1 .

\subsubsection{Thermal Effusivity}

A trend of decreasing thermal effusivity with corresponding decrease of sand content for all the mixing ratio, $\mathrm{T}_{1}$ to $\mathrm{T}_{5}$ (mortar) and $\mathrm{T}_{11}$ to $\mathrm{T}_{55}$ (concrete) for all the sand types. The thermal effusivity of parametric mortar blocks lie in the range of $460 \mathrm{Ws}^{1 / 2} / \mathrm{m}^{2} \mathrm{~K}$ to $890 \mathrm{Ws}^{1 / 2} / \mathrm{m}^{2} \mathrm{~K}$ for the different mixing ratios, with the lowest being achieved by the mixed builder's and washed sand blocks as presented in Figure 13. Among the builder's sand and washed sand blocks, the lowest thermal effusivity were achieved by the ratios with 1 part of cement to 2 parts of sand as $610 \mathrm{Ws}^{1 / 2} / \mathrm{m}^{2} \mathrm{~K}\left(\mathrm{MbsT}_{5}\right)$ and $605 \mathrm{Ws}^{1 / 2} / \mathrm{m}^{2} \mathrm{~K}\left(\mathrm{Mbs}_{5}\right)$ for builder's sand and washed sand types respectively. For each sand type, there was a general decrease in thermal effusivity form the $\mathrm{T}_{1}$ ratio to the $\mathrm{T}_{5}$ ratio with a decrease of about 27\% (builder's), 32\% (washed) and 49\% (combined).

Table 1. An example of calculated thermo-physical properties.

\begin{tabular}{cccc}
\hline Building Component & $\begin{array}{c}\text { Thermal } \\
\text { Conductivity } \\
(\mathrm{W} / \mathrm{mK})\end{array}$ & $\begin{array}{c}\text { Thermal } \\
\text { Resistance } \\
\left(\mathrm{m}^{2} \mathrm{~K} / \mathrm{W}\right)\end{array}$ & $\begin{array}{c}\text { Thermal } \\
\text { Transmittance } \\
\text { (U-value) }\left(\mathrm{W} / \mathrm{m}^{2} \mathrm{~K}\right)\end{array}$ \\
\hline $\begin{array}{c}\text { A single leaf wall (mortar block with } \\
\text { internal and external plaster) }\end{array}$ & 0.405 & 0.377 & 2.65 \\
\hline
\end{tabular}


The parametric concrete blocks also achieved decreasing thermal effusivity among various ratios from $T_{11}$ to $T_{55}$ the three types of sand of about $18 \%$ (builder's), $13 \%$ (washed) and 9\% (combined) as presented in Figure 14. However, the $\mathrm{T}_{11}$ ratio achieved relatively lower thermal effusivity that the corresponding mortar blocks and a higher thermal effusivity than the mortar blocks for the $\mathrm{T}_{55}$ ratios. Among the builder's sand, washed sand and the combined sand concrete blocks, the lowest thermal effusivity achieved were $610 \mathrm{Ws}^{1 / 2} / \mathrm{m}^{2} \mathrm{~K}\left(\mathrm{Mbs}_{55}\right), 605 \mathrm{Ws}^{1 / 2} / \mathrm{m}^{2} \mathrm{~K}$ $\left(\mathrm{bsT}_{55}\right)$ and $605 \mathrm{Ws}^{1 / 2} / \mathrm{m}^{2} \mathrm{~K}\left(\mathrm{MbsT}_{55}\right)$ respectively.

This result shows a linear relationship between thermal conductivity and thermal effusivity as the thermal effusivity increases with decreasing thermal conductivity. This result is in agreement with [39]. Moreover, the parametric concrete blocks achieved a relatively narrow drop of both thermal conductivity and thermal effusivity among the ratios for all the sand types tested.

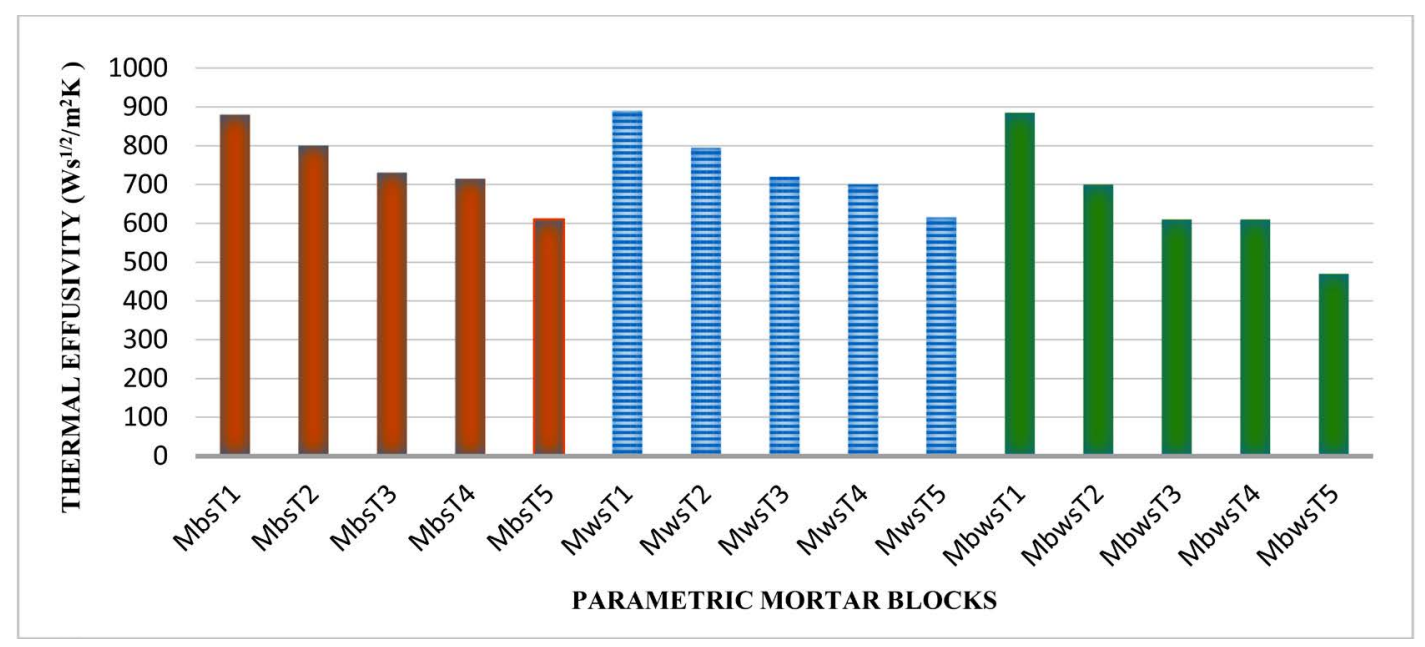

Figure 13. Comparison of average thermal effusivity of polymer test method for parametric mortar blocks.

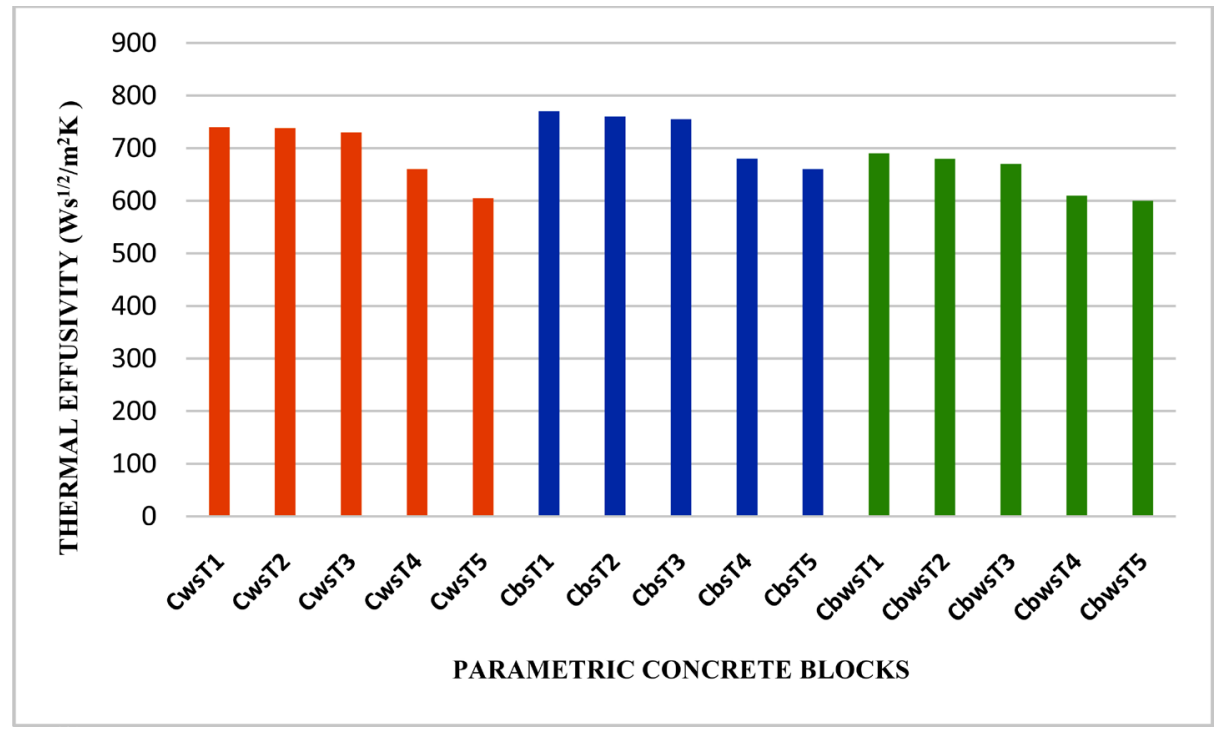

Figure 14. Comparison of average thermal effusivity of polymer test method for parametric concrete blocks. 


\section{Conclusions and Recommendations}

This paper presents the results of an experimental study characterizing the thermo-physical properties of cement-based building fabrics in Ghana using a cost-effective enhancement approach. The thermo-physical properties of analyzed building fabric samples selected from manufacturing companies and that of parametric blocks were found to meet the range of standards outlined in CIBSE Guide A.

This established thermo-physical properties of the varied ratios of cement-based blocks (mortar and concrete) implies that simulation works involved in thermal building performance analysis in Ghana, can be accurately done. As a recommendation, the incorporation of technology and additives could be explored in the design and manufacturing of building fabrics to achieve the thermal transmittance specified for building envelopes in building regulations. Moreover, there is the need for studies to establish other properties such as density of mortar and concrete blocks made from the locally available materials.

\section{Conflicts of Interest}

The authors declare no conflicts of interest regarding the publication of this paper.

\section{References}

[1] Mohamed, A., Hasan, A. and Sirén, K. (2014) Fulfillment of Net-Zero Energy Building (NZEB) with Four Metrics in a Single Family House with Different Heating Alternatives. Applied Energy, 114, 385-399. https://doi.org/10.1016/j.apenergy.2013.09.065

[2] Baetens, R., De Coninck, R., Van Roy, J., Verbruggen, B., Driesen, J. and Helsen, L. (2012) Assessing Electrical Bottlenecks at Feeder Level for Residential Net Zero-Energy Buildings by Integrated System Simulation. Applied Energy, 96, 74-83. https://doi.org/10.1016/j.apenergy.2011.12.098

[3] Fong, K.F. and Lee, C.K. (2012) Towards Net Zero Energy Design for Low-Rise Residential Buildings in Subtropical Hong Kong. Applied Energy, 93, 686-694. https://doi.org/10.1016/j.apenergy.2012.01.006

[4] Leckner, M. and Zmeureanu, R. (2011) Life Cycle Cost and Energy Analysis of a Net Zero Energy House with Solar Combisystem. Applied Energy, 88, 232-241. https://doi.org/10.1016/j.apenergy.2010.07.031

[5] Becchio, C., Corgnati, S.P., Monetti, V. and Fabrizio, E. (2014) From High Performing Buildings to Nearly Zero Energy Buildings: Potential of an Existing Office Building. In: Arisoy, P.D.A., Ed., Climamed 13 Proceedings Mediterranean Congress of Climatalization Proceedings Book, Turkish Society of HVAC and Sanitary Engineers, Istanbul, 72-81.

[6] Santamouris, M. and Kolokotsa, D. (2013) Passive Cooling Dissipation Techniques for Buildings and Other Structures: The State of the Art. Energy and Buildings, 57, 74-94. https://doi.org/10.1016/j.enbuild.2012.11.002

[7] Anais, J., Regis, O. and Xavier, P. (2013) Selection Criteria of Thermal Mass Materials for Low Energy Building Construction Applied to Conventional and Alternative Materials. Energy and Buildings, 63, 36-48.

https://doi.org/10.1016/j.enbuild.2013.03.047 
[8] Yu, R., Spiesz, P. and Brouwers, H.J.H. (2015) Development of an Eco-Friendly Ultra-High Performance Concrete (UHPC) with Efficient Cement and Mineral Admixtures Uses. Cement and Concrete Composites, 55, 383-394. https://doi.org/10.1016/j.cemconcomp.2014.09.024

[9] Chabannes, M., Benezet, J.-C., Clerc, L. and Garcia-Diaz, E. (2014) Use of Raw Rice Husk as Natural Aggregate in a Lightweight Insulating Concrete: An Innovative Application. Construction and Building Materials, 70, 428-438. https://doi.org/10.1016/j.conbuildmat.2014.07.025

[10] Amos-Abanyie, S., Akuffo, F.O. and Kuting-Sanwu, V. (2013) Effects of Thermal Mass, Window Size and Night-Time Ventilation on Peak Indoor Air Temperature in the Warm-Humid Climate of Ghana. The Scientific World, 9, Article ID: 621095. https://doi.org/10.1155/2013/621095

[11] Kendrick, C., Ogden, R., Wang, X. and Baiche, B. (2012) Thermal Mass in New Build UK Housing: A Comparison of Structural Systems in a Future Weather Scenario. Energy and Buildings, 48, 40-49. https://doi.org/10.1016/j.enbuild.2012.01.009

[12] Sadineni, S.B., Madala, S. and Boehm, R.F. (2011) Passive Building Energy Savings: A Review of Building Envelope Components. Renewable and Sustainable Energy Review, 15, 3617-3631. https://doi.org/10.1016/j.rser.2011.07.014

[13] Koranteng, C. (2010) Energy Performance of Office Buildings in Ghana. Journal of Science and Technology, 30, 114-127. https://doi.org/10.4314/just.v30i2.60542

[14] Radhi, H. (2009) Can Envelope Codes Reduce Electricity and $\mathrm{CO}_{2}$ Emissions in Different Types of Buildings in the Hot Climate of Bahrain. Energy, 34, 205-215. https://doi.org/10.1016/j.energy.2008.12.006

[15] Iwaro, J. and Mwasha, A. (2010) A Review of Building Energy Regulation and Policy for Energy Conversation in Developing Countries. Energy Policy, 38, 7744-7755. https://doi.org/10.1016/j.enpol.2010.08.027

[16] Givoni, B. (2011) Indoor Temperature Reduction by Passive Cooling Systems. Solar Energy, 85, 1692-1726. https://doi.org/10.1016/j.solener.2009.10.003

[17] Escriva-Escriva, G. (2011) Basis Actions to Improve Energy Efficiency in Commercial Buildings in Operation. Energy and Building, 43, 3106-3111. https://doi.org/10.1016/j.enbuild.2011.08.006

[18] Darkwa, J., Su, O. and Zhou, T. (2012) Development of Non-Deform Micro-Encapsulated Phase Change Energy Storage Tablets. Applied Energy, 98, 441-447. https://doi.org/10.1016/j.apenergy.2012.04.006

[19] Ballarini, I. and Corrado, V. (2012) Analysis of the Building Energy Balance to Investigate the Effect of Thermal Insulation in Summer Conditions. Energy and Buildings, 52, 168-180. https://doi.org/10.1016/j.enbuild.2012.06.004

[20] Buker, M.S., Mempouo, B. and Riffat, S.B. (2015) Experimental Investigation of a Building Integrated Photovoltaic/Thermal Roof Collector Combined with a Liquid Desiccant Enhanced Indirect Evaporative Cooling System. Energy Conversion and Management, 101, 239-254. https://doi.org/10.1016/j.enconman.2015.05.026

[21] Adjei, E., Omer, S. and Wu, Y.P. (2015) Potential Integration of Sustainable Technology in Office Building in Ghana: Exploratory Study. 14th International Conference on Sustainable Energy Technologies-SET, Nottingham, UK, 25-27 August 2015.

[22] Oppong, R.A. and Badu, E. (2012) Building Material Preferences in Warm-Humid and Hot-Dry Climates in Ghana. Journal of Science and Technology, 32, 24-37. https://doi.org/10.4314/just.v32i3.4 
[23] Laaroussi, N., Cherki, A., Garoum, M., Khabbazi, A. and Feiz, A. (2013) Thermal Properties of a Sample Prepared Using Mixtures of Clay Bricks. Energy Procedia, 42, 337-346. https://doi.org/10.1016/j.egypro.2013.11.034

[24] Gyimah, K.A. (2019) Windows for Quality Indoor Environment: A Case of Offices in the Warm-Humid Climate of Kumasi, Ghana. PhD Thesis, Department of Architecture, KNUST, Kumasi.

[25] Simons, B. (2015) Simulation-Based Exploration of the Thermal Performance of some Multi Storey Office Buildings in Accra, Ghana. PhD Thesis, Department of Building Technology, KNUST, Kumasi.

[26] Rübner, K. and Hoffmann, D. (2006) Characterization of Mineral Building Materials by Mercury-Intrusion Porosimetry. Particle \& Particle Systems Characterization, 23, 20-28. https://doi.org/10.1002/ppsc.200601008

[27] ISO 8302 (1991) Thermal Insulation-Determination of Steady-State Thermal Resistance and Related Properties-Guarded Hot Plate Apparatus.

[28] ASTM C177-04 (2004) Standard Test Method for Steady-State Heat Flux Measurements and Thermal Transmission Properties by Means of the Guarded-Hot-Plate Apparatus. ASTM International, West Conshohocken, PA. https://www.astm.org

[29] ASTM D7984-16 (2016) Standard Test Method for Measurement of Thermal Effusivity of Fabrics Using a Modified Transient Plane Source (MTPS) Instrument. ASTM International, West Conshohocken, PA. https://www.astm.org

[30] C-Therm TCi Operator Manual. C-Therm Technologies.

[31] BS 1199 and 1200 (1976) Specifications for Building Sands from Natural Sources.

[32] ASTM C33, Standard Specification for Concrete Aggregates.

[33] BS EN 12390-1 (2012) Testing Hardened Concrete. Shape, Dimensions and Other Requirements for Specimens and Moulds.

[34] BS EN 12390-2 (2009) Testing Hardened Concrete. Making and Curing Specimens for Strength Tests STANDARD. British-Adopted European Standard.

[35] BS EN 1367-4 (2008) Tests for Thermal and Weathering Properties of Aggregates. Determination of Drying Shrinkage STANDARD. British-Adopted European Standard.

[36] Bahar, R., Benazzoug, M. and Kenai, S. (2004) Performance of Compacted Cement Stabilized Soil. Cement and Concrete Composites, 25, 633-641.

https://doi.org/10.1016/S0958-9465(02)00077-X

[37] Akinmusuru, J.O. (1995) Thermal Conductivity of Earth Blocks. Journal of Materials in Civil Engineering, 6, 341-351. https://doi.org/10.1061/(ASCE)0899-1561(1994)6:3(341)

[38] Reddy Venkatarama, B.V. and Gupta, A. (2006) Tensile Bond Strength of Soil-Cement Block Masonry Couplets Using Cement-Soil Mortars. Journal of Materials in Civil Engineering, 18, 36-45. https://doi.org/10.1061/(ASCE)0899-1561(2006)18:1(36)

[39] Milon, K.H., Rashid, M.H., Debashis, M. and Tozammel, H. (2012) Effects of Aggregate Types on Thermal Properties of Concrete. ARPN Journal of Engineering and Applied Sciences, 7, 900-907. 